\title{
Diseño e implementación de un sistema de visión por computadora para el reconocimiento de objetos en movimiento
}

\section{Design and implementation of a computer vision system for object recognition in movement}

TORRES-BECERRA, Franco Javier ${ }^{1} \dagger$, GUZMAN-ALTAMIRANO, Miguel Angel ${ }^{1}$, GARCÍAGALLEGOS, Jesús Hazael ${ }^{2}$ y CABAL-VELARDE, Javier Gustavo ${ }^{1 *}$

\author{
${ }^{1}$ Instituto Tecnológico Superior de Irapuato, Carretera Irapuato-Silao km 12.5 C.P. 36821, Irapuato, Gto., México. \\ ${ }^{2}$ Universidad Tecnológica de San Juan del Río Querétaro, División de Energías Renovables, Av. La Palma No. 125, Vista \\ Hermosa, 76800, San Juan del Río, Querétaro, México
}

\author{
ID $1^{\mathrm{er}}$ Autor: Franco Javier, Torres-Becerra / ORC ID: 0000-0001-9018-1076, CVU CONACYT ID: 1016034 \\ ID $1{ }^{\text {er }}$ Coautor: Miguel Angel, Guzman-Altamirano / ORC ID: 0000-0002-6520-7382, CVU CONACYT ID: 170684 \\ ID $2^{\text {do }}$ Coautor: Jesús Hazael, Garcia-Gallegoz, ORC ID: 0000-0002-9909-8882 / CVU CONACYT ID 175436 \\ ID $3^{\text {er }}$ Coautor: Javier Gustavo, Cabal-Velarde / ORC ID: 0000-0002-5516-3849, CVU CONACYT ID 99159
}

DOI: $10.35429 / \mathrm{JCS} .2019 .8 .3 .1 .13$

Recibido: 12 de Marzo, 2019; Aceptado 30 de Junio, 2019

\begin{abstract}
Resumen
En este trabajo desarrollamos un sistema de visión por computadora que permite el reconocimiento de figuras geometricas en movimiento mediante una camara web en tiempo real, así como la identificación del tamaño del objeto basado en un objeto conocido. Para la realización de éste se utilizaron diversas técnicas del procesamiento digital de imágenes como filtros de escala a grises ya que es el primer paso para empezar a realizar el procesamiento de imagenes, umbralización para hacer la transformación de la imagen en forma binaria donde el 1 es el color blanco y 0 es el color negro; detección de bordes para la detección de los contornos de las figuras, a su vez un parámetro importante es la eliminación del ruido en la señales obtenidas, por lo que se utilizaron filtros digitales los cuales permiten eliminar oscilaciones de las señales. Como posibles aplicaciones pueden ser la detección de microorganismos en ambientes controlados de acuerdo a su morfología, asi como su crecimiento del área en tiempo real.
\end{abstract}

Visión, Computadora, Procesamiento

\begin{abstract}
In this work we developed a computer vision system that allow the geometric figures recognition in real time using a web camera, also the identification of the objects size using a known object. To make this possible we used several techniques of the digital image processing as gray scale filters because that's the first step to start the image processing, threshold to make the image transformation in binary form where 1 is the white color and 0 the black color, edge detection to detect the edges of the figures therefore an important parameter is the noise cancelation of the obtained signals, that's the reason of the using of digital filters because those allow the oscillation cancelation in the signals. The possible application can be the microorganism detection in controlled environments accord of its morphology also the change of its area in real time.
\end{abstract}

Vision, Computer, Processing

Citación: TORRES-BECERRA, Franco Javier, GUZMAN-ALTAMIRANO, Miguel Angel, GARCÍA-GALLEGOS, Jesús Hazael y CABAL-VELARDE, Javier Gustavo. Diseño e implementación de un sistema de visión por computadora para el reconocimiento de objetos en movimiento. Revista de Simulación Computacional. 2019. 3-8: 1-13

\footnotetext{
* Correspondencia al Autor: (javelarde@itesi.edu.mx)

$\uparrow$ Investigador contribuyendo como primer autor.
} 


\section{Introducción}

Las variadas técnicas de procesamiento digital de imágenes, han permitido la elaboración de sistemas reconocedores de patrones, como es el caso del presente trabajo. El reconocimiento de patrones en tiempo real lleva procesados $\mathrm{y}$ filtrados de imagen, ya que existen diversas anomalías que afectan la identificación de estos. Estarita y colaboradores en el 2017 [1] desarrollaron un sistema con visión artificial para el reconocimiento de un objeto, el cual será detectado a través de una cámara Web permitiendo que el software del sistema por medio de análisis de patrones determine si este coincide con alguno de los objetos previamente registrados en una base de datos.

Uno de los campos con mayor proyección dentro de la Visión Artificial es el relacionado con el Reconocimiento Biométrico Facial, el cual se centra en el mismo identificador que utilizamos los humanos para distinguir una persona de otra: su rostro. Por tanto, uno de los objetivos principales es comprender el complejo sistema visual humano y como se representan los rostros para lograr discriminar identidades con exactitud. En el año 2017 Caballero y colaboradores[2] estudiaron los diferentes métodos y algoritmos que permiten detectar un rostro en una imagen, y desarrollar una aplicación que pueda ser entrenada para realizar el reconocimiento de una persona especifica dentro de la imagen.

Marino Vera y colaboradores[3] en el 2017 elaboraron un algoritmo automático para el reconocimiento de variables antropométricas, se probó con dos pacientes, logrando un porcentaje de error general del sistema de 2,81\%. El desarrollo del proyecto permirá al especialista apoyarse en una herramienta digital para lograr medidas más precisas, mejorando la exactitud y la precisión en el diagnóstico.

Rosales Romero en el 2017[4] desarrolló un prototipo de detección de visión artificial para mejorar la comunicación con niños que tienen parálisis cerebral, enfocando dicho proyecto a un caso de estudio en específico; donde, se puedan detectar sus expresiones corporales mediante Visión Artificial.
Ruiz Sarmiento y colaboradores en el año 2017[5] realizaron un trabajo donde buscaron dar indicaciones útiles sobre el modelado de información contextual utilizando CRFs como herramienta para el modelado y aprovechamiento del contexto.

\section{Metodología}

La metodología propuesta para el desarrollo del sistema se muestra en la figura 1.

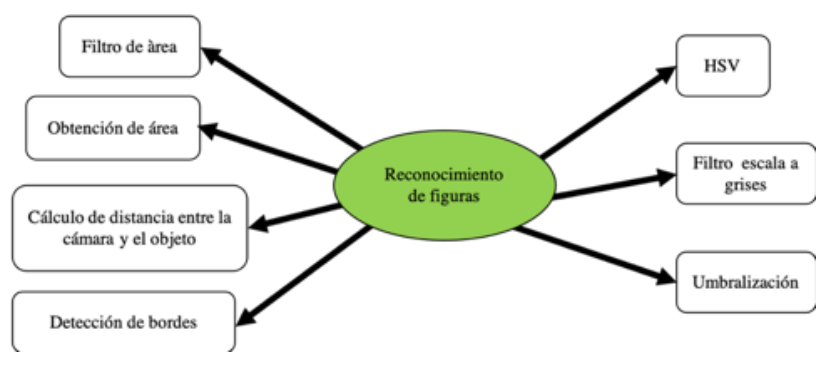

Figura 1 Metodología propuesta

\section{Algoritmo}

Para la elaboración del sistema se realizo la elaboración de un algoritmo, el cual permite obtener el nombre de la figura y su área, éste se muestra en la figura 2.

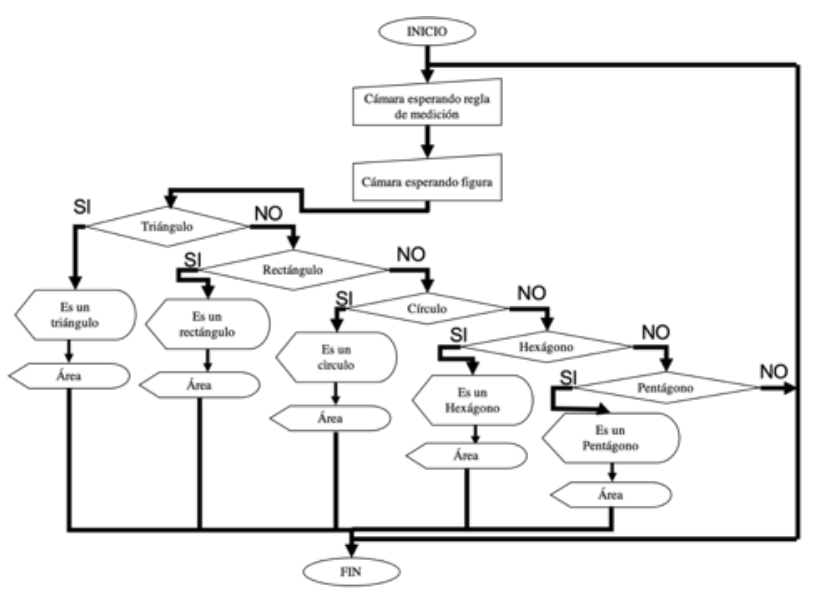

Figura 2 Algoritmo propuesto

\section{Modelo de color RGB}

En el modelo de color RGB (Red, Green, Blue) cada color aparece en las componentes espectrales primarias de rojo, verde y azul. El color de un pixel se compone de las tres componentes mencionadas, en el modelo de color RGB una imagen puede ser representada por una función de intensidad mostrada en la ecuación $1[6,7]$ : 


$$
I_{R G B}=\left(F_{R}, F_{G}, F_{B}\right)
$$

Donde:

$F_{R}$ : Es la intensidad en color rojo de un pixel $F_{G}$ : Es intensidad en color verde de un pixel $F_{B}$ : Es la intensidad en color azul de un pixel

La intensidad de cada color se guarda usualmente usando 8 bits, el cual indica que el nivel de cuantización es de 256 por lo que si se toman los 3 canales para conformar el pixel entonces un pixel ocupa 24 bits lo que viene siendo 256 × $3=16777216$ combinaciónes de colores posibles. En la figura 3 se muestra una imagen utilizando el modelo RGB.
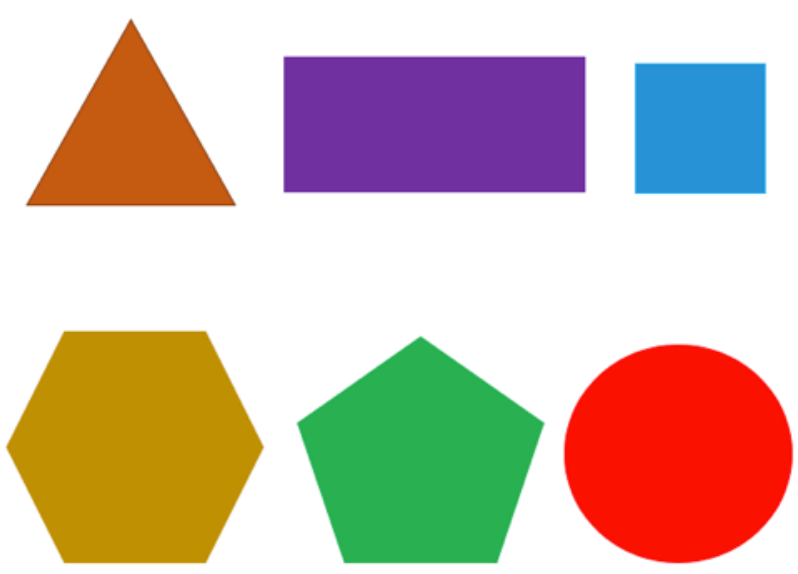

Figura 3 Imagen en modelo RGB

\section{HSV (Hue, Saturation, Value)}

El modelo de color de Matiz Saturación y valor (HSV por sus siglas en ingles) describe los colores en terminos de la Matiz, Saturación, Valor (Hue, Saturation, Value) donde La matiz representa el tipo de color, este puede ser describido como un circulo que contiene 360 grados, donde 0 grados es el color rojo. La saturación representa la vibranza del color, el rango de valores es de $[0,255]$ donde una saturación baja provoca que la imagen se turne a color gris y saturación alta, colores vivos, en la figura 4 se muestra lo mencionado.
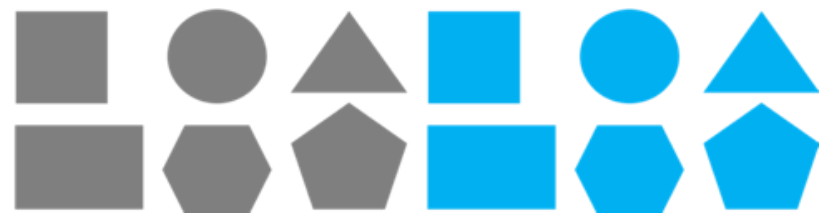

Figura 4 Saturación baja (izquierda), saturación alta (derecha)

El valor representa el brillo que tendra la imagen su rango es de $[0,255]$ donde 0 es un color negro y 255 un color blanco.
En la figura 5 se muestra el espacio de color HSV como una rueda de color.

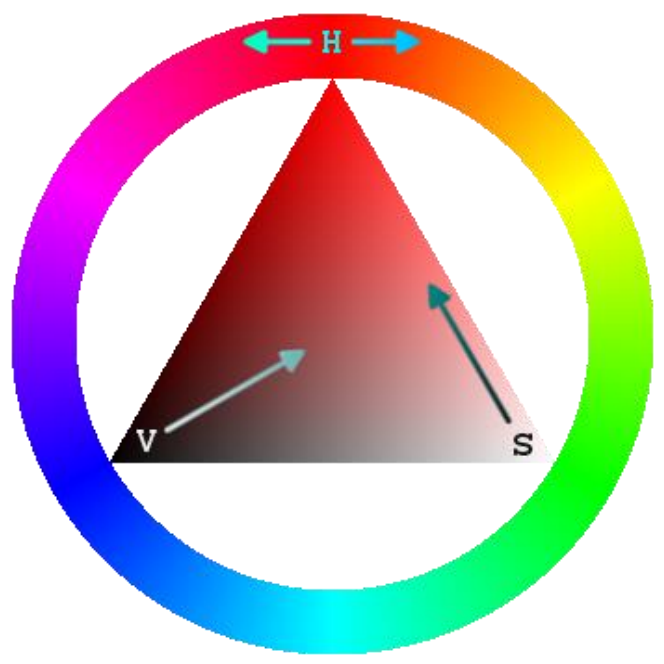

Figura 5 Espacio de color HSV

\section{Filtro escala a grises}

El filtro a escala a grises es una técnica del procesamiento digital de imágenes, existen diferentes clases de matrices como la uint 8 la cual el rango de valores es de [0,255], para uint 16 el rango es de $[0,65535]$ y finalmente para int16 el rango es de [-32768, 32767] [7].

La conversión de RGB a escala a grises es necesaria para el procesamiento y extracción de características, por lo que la ecuación 2 describe la conversión[8]:

$$
Y=0.299 R+0.587 G+0.114 B
$$

En la figura 6 se muestra una imagen a escala de grises.

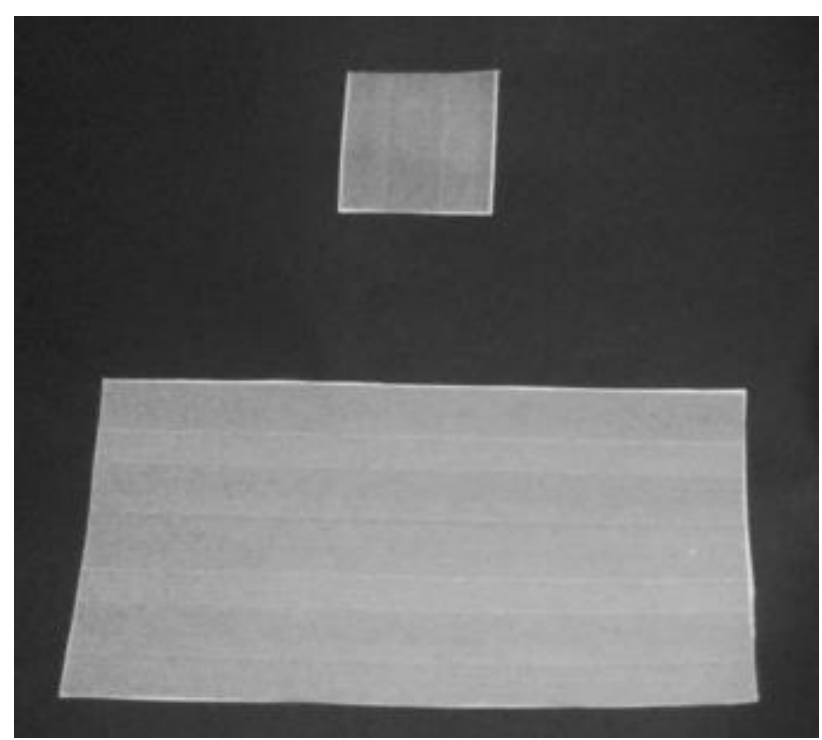

Figura 6 Imagen en escala a grises

TORRES-BECERRA, Franco Javier, GUZMAN-ALTAMIRANO, Miguel Angel, GARCÍA-GALLEGOS, Jesús Hazael y CABAL-VELARDE, Javier Gustavo. Diseño e implementación de un sistema de visión por computadora para el reconocimiento de objetos en movimiento. Revista de Simulación Computacional. 2019 


\section{Umbralización}

La umbralización o binarización es un metodo del procesamiento digital de imágenes que se utiliza para colocar en 0 (negro) o en 1 (blanco) cada pixel de una imagen. El valor umbral es necesario ya que con este se determina el comportamiento del pixel, la ecuación 3 muestra que si el valor de cada pixel es mayor al umbral entonces este tomara el valor de 1 pero si el valor de cada pixel es menor entonces tomara el valor de 0 :

$$
g(x, y)= \begin{cases}1, & f(x, y)>T \\ 0, & f(x, y) \leq T\end{cases}
$$

Donde:

$g(x, y)$ : Es la imagen

$f(x, y)$ : Es un pixel de la imagen

$T$ : Es el valor umbral

Para la visualización del efecto de esta formula, como ejemplo se coloca una matriz de $3 \mathrm{X} 3$ simulando que se tienen 9 pixeles con cierto nivel de gris donde el umbral es de 200 (figura 7 a) y otra matriz de la misma dimensión ya umbralizada como se muestra en la figura $7 \mathrm{~b}$ ).

\begin{tabular}{|c|c|c|}
\hline 100 & 255 & 90 \\
\hline 220 & 50 & 210 \\
\hline 130 & 240 & 100 \\
\hline
\end{tabular}

a)

\begin{tabular}{|l|l|l|}
\hline 0 & 1 & 0 \\
\hline 1 & 0 & 1 \\
\hline 0 & 1 & 0 \\
\hline
\end{tabular}

b)
Figura 7 a) Matriz original b) Matriz umbralizada

Un ejemplo y aplicación de la umbralización se puede observar en la figura 8(a) donde se muestra una figura en escala a grises; y en la figura 8(b) la imagen umbralizada donde gracias a la utilización de un valor umbral es posible eliminar algunas zonas no deseadas en una imagen [9-12].
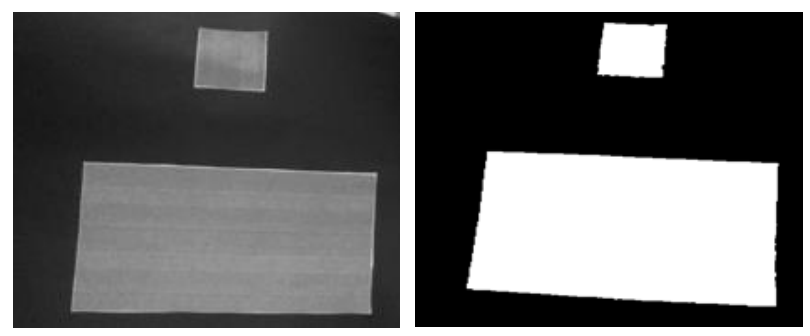

Figura 8 a) Imagen en escala a grises b) Imagen umbralizada

\section{Detección de bordes}

La detección de bordes es un metodo importante de la segmentación dentro del procesamiento digital de imágenes, pero, ¿Qué se considera un borde?, un borde es considerado como un conjunto de pixeles conectados que se encuentran en el limite entre dos regiones. Un borde puede ser medido de acuerdo a la transición de los niveles de gris, la figura 9 (a) muestra un borde ideal digital y la figura 9(b) muestra un borde real.
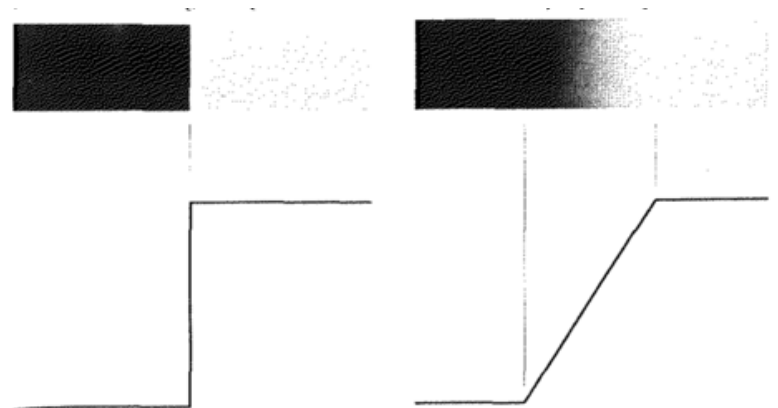

Figura 9 a) Borde ideal

Figura 9 b) Borde rampa o real

Para la detección de bordes se utiliza el metodo del la detección del gradiente del borde, ya que este es uno de los mas utilizados donde la imagen esta cubierta con dos gradientes uno en la dirección $\mathrm{X}$ y el otro gradiente en la dirección $\mathrm{Y}$. El gradiente es el equivalente bidimensional de la primera derivada y se define como el vector de gradiente mostrado en la ecuación 4 :

$$
\nabla f(x, y)=g=\left[\begin{array}{l}
g_{x} \\
g_{y}
\end{array}\right]
$$

Donde:

$\nabla f(x, y):$ Es el gradiente equivalente bidimencional

$g_{x}$ : Es el gradiente en la dirección X

$g_{y}:$ Es el gradiente en la dirección Y

Los dos gradientes se calculan en cada pixel con las ecuación 5 para $g_{x}$ y ecuación 6 para $g_{y}$

$$
\begin{aligned}
& g_{x}=f(x+1, y)-f(x, y) \\
& g_{y}=f(x, y+1)-f(x, y)
\end{aligned}
$$

A su vez se puede obtener la maginitud del gradiente con la ecuación 7 y su ángulo con la ecuación 8[13]:

$$
|g|=\sqrt{g_{x}^{2}+g_{y}^{2}}
$$




$$
\theta=\tan ^{-1}\left(\frac{g_{y}}{g_{x}}\right)
$$

En la figura 10 se puede observar la imagen original, la figura 11 la figura a escala a grises, mientras que la figura 12 se observan los bordes extraidos de la imagen original $[9,13$, 14].

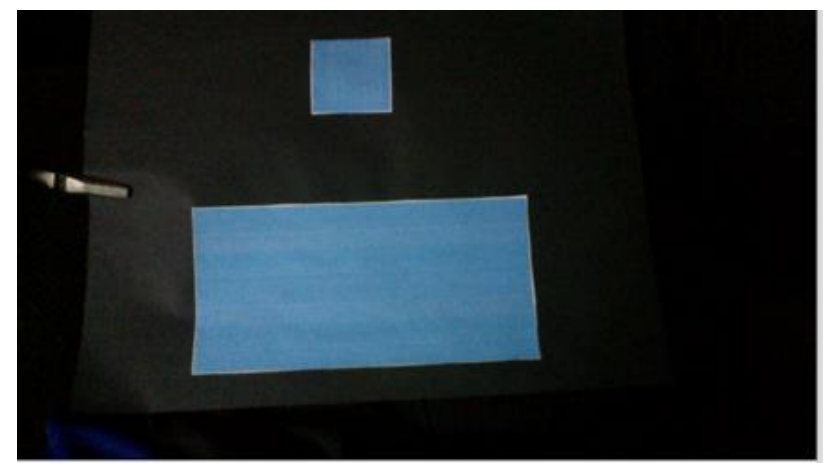

Figura 10 Imagen antes del procesado

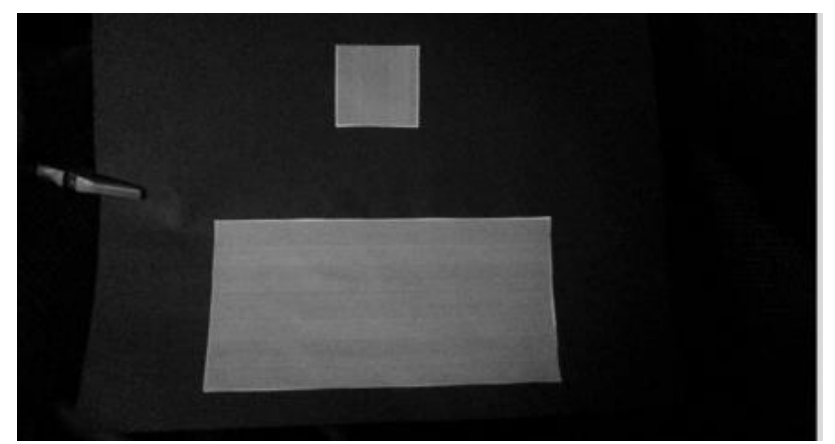

Figura 11 Imagen convertida a escala a grises

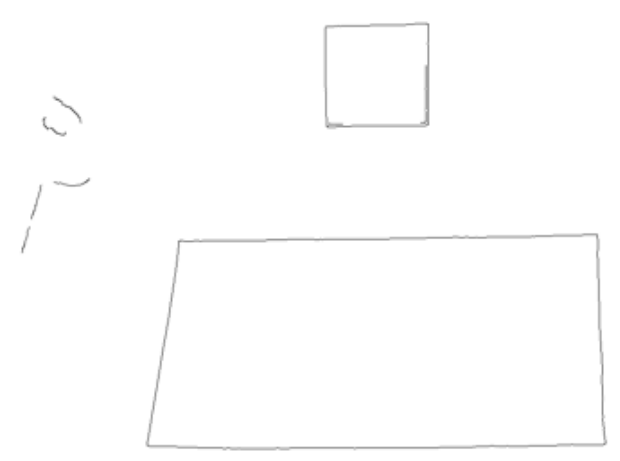

Figura 12 Imagen donde se muestran los bordes extraidos de la figura original

\section{Medición de la distancia entre un objeto y la cámara}

La cámara estenopeica (monocular) genera una relación de uno a uno entre el objeto y la imagen. Usando este principio, se puede deducir una relación entre los parámetros conocidos: distancia focal (f), radio del marcador en el plano de la imagen ( $r$ ) y radios del marcador en el plano del objeto $(\mathrm{R})$ y parámetro desconocido, distancia desde la cámara hasta El objeto (d)[15].

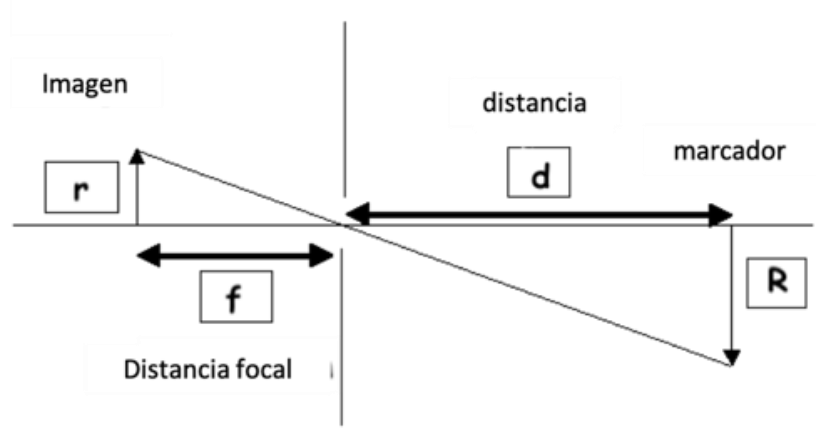

Figura 13 Formación del los triangulos semejantes[15]

\section{Filtro EMA}

Este es un filtro digital utilizado para atenuar ruido en las señales, su ecuación es la siguiente[16]:

$$
y[n]=\alpha x[n]+(1-\alpha) y[n-1]
$$

Donde:

$\alpha$ : Coeficiente de atenuación de la señal

\section{Polígono de aproximación a contornos de la figura}

Al momento de tratar de analizar la mofología de una figura circular se tuvo el problema de que esta no tiene aristas, por lo que no seria posible su reconocimiento, debido a esto se trazo un poligono de aproximación al contorno, ya que este contará con un numero determinado de aristas, esto se puede observar en la figura 914. 


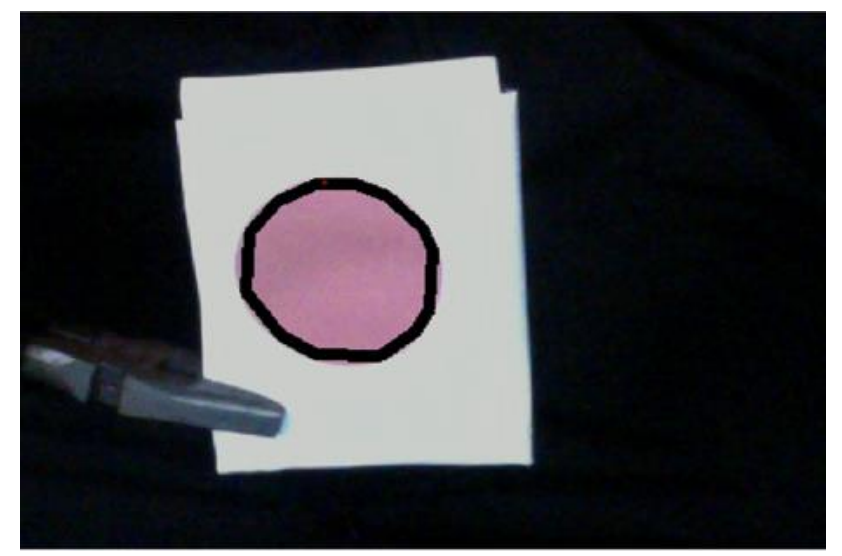

Figura 14 Poligono trazado en la aproximación de los bordes de la imagen

\section{Reconocimiento de figura de acuerdo a su morfología}

El reconocimiento de la figura se realizo de acuerdo al numero de aristas del poligono generado, por lo que se hicieron pruebas con diferentes figuras, en la figura 15 se muestra la identificación de una figura circular, en la figura 16 se muestra el reconocimiento de una figura rectangular y una cuadrada.

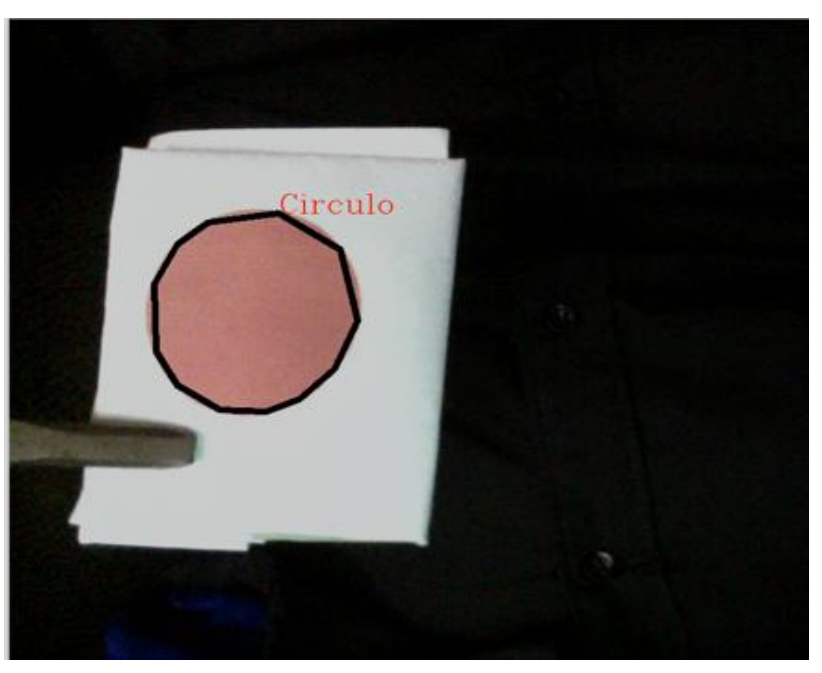

Figura 15 Reconocimiento de un circulo

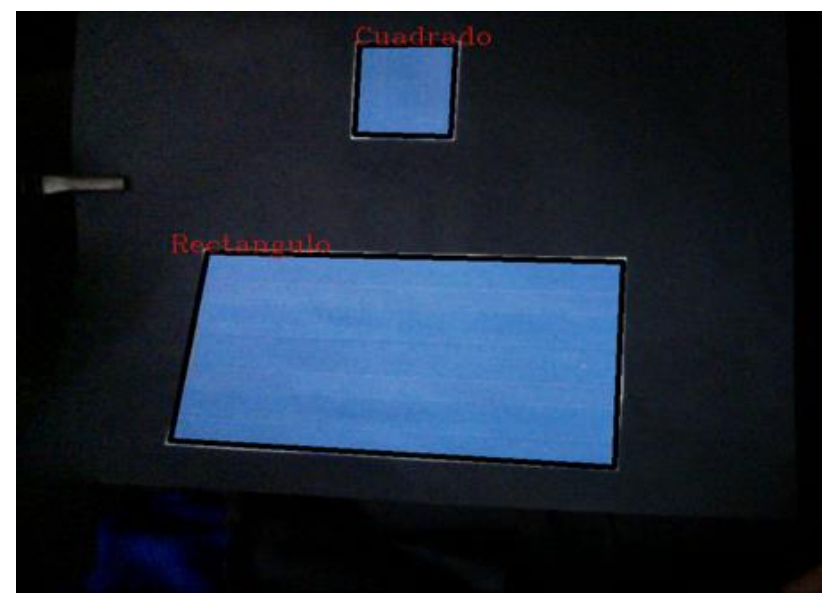

Figura 16 Reconocimiento de un cuadrado y un rectangulo

\section{Obtención de pixeles de una figura para el} calculo de área

Para obtener el área de una figura en tiempo real existen dos problemas, el primero es que al acercar o alejar la figura de la cámara el numero de pixeles que conforman la figura cambia, en la figura 17 se puede observar el numero de pixeles que conforman la figura cuando esta se aleja y en la figura 18 se obseva el numero de pixeles que conforma la figura cuando esta se acerca.

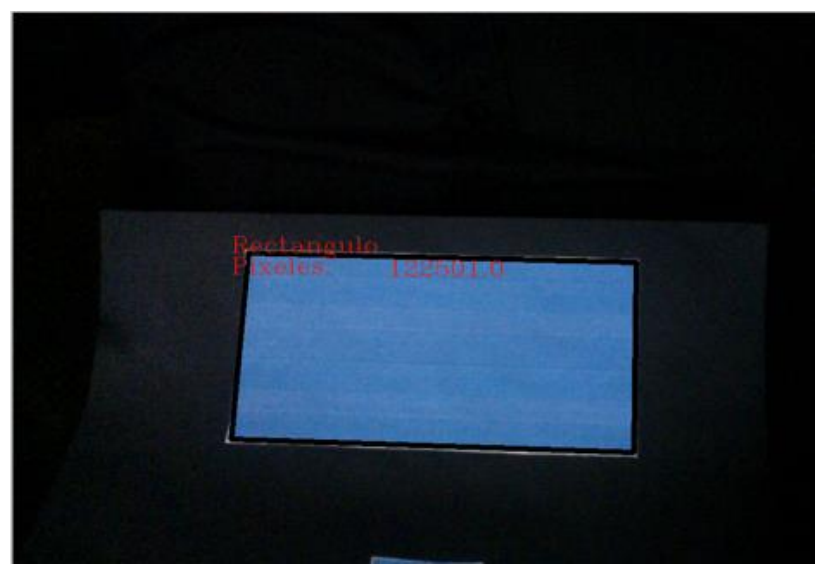

Figura 17 Numero de pixeles que conforman la figura cuando se aleja, pixeles $=122501$

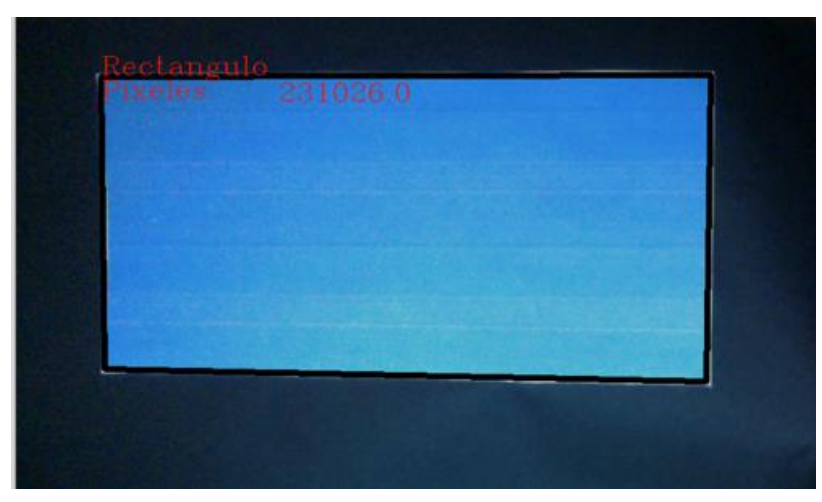

Figura 18 Numero de pixeles que conforman la figura cuando se acerca, pixeles $=231026$

Como se observo en las figuras anteriores el numero de pixeles incrementa o decrementa al acercar o alejar la figura, esto repercute al calcular el area, ya que esta cambiaría al mover la figura de lugar.

\section{Area de una figura obtenida apartir de una regla de medición}

Para obtener el área de una figura se utilizo una regla de medición como base, la regla de medición es un cuadrado de dimensiones $4 \mathrm{~cm} \mathrm{X}$ $4 \mathrm{~cm} \mathrm{y} \mathrm{su} \mathrm{area} \mathrm{es} 16 \mathrm{~cm}^{2}$, esta regla es indispensable colocarla junto a la figura a la cual se quiere obtener el área. 
Al utilizar la regla de medición se puede dimensionar el numero de pixeles de la figura gracias al área ya conocida de la regla de medición y con esto es posible determinar el área de una figura, en la figura 19 se observa el área de la figura cuando esta se encuentra alejada y en la figura 20 se observa el área de la figura cuando esta se encuentra cerca.

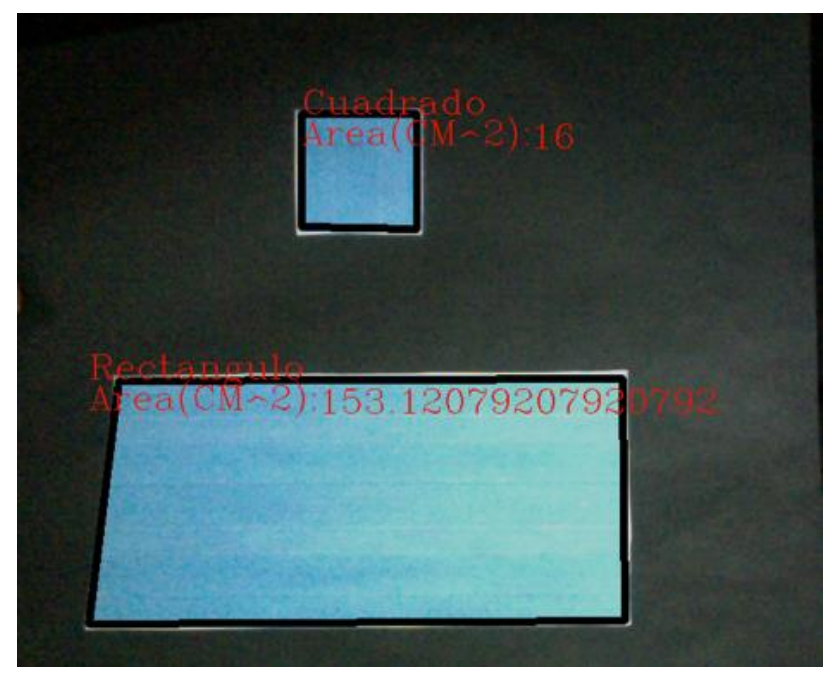

Figura 19 Area del rectangulo cuando esta cerca la figura

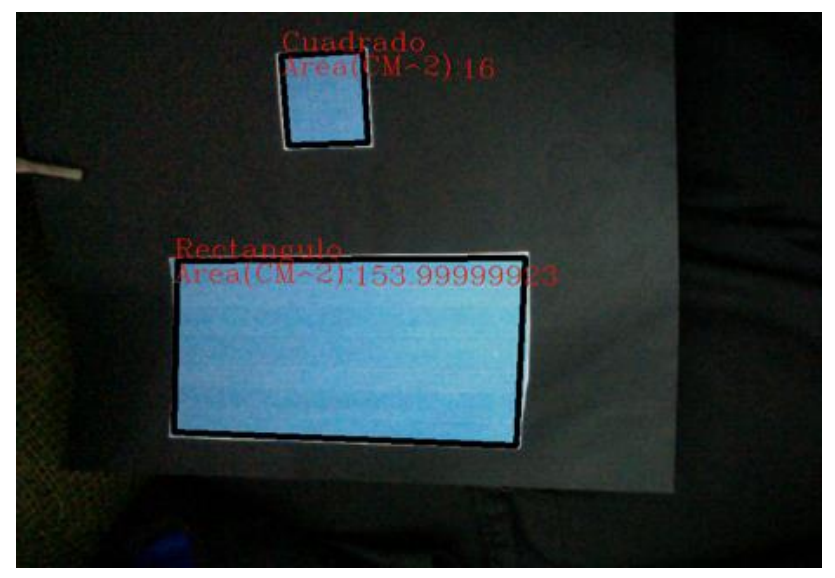

Figura 20 Area del rectangulo cuando esta lejos la figura

\section{Variación del area con respecto a la distancia}

Para determinar si existe alguna variación del área de las figuras, se hicieron cinco pruebas por figura, las figuras analizadas son cinco, rectángulo, triángulo, hexágono, pentágono y círculo, a su vez se muestra una gráfica donde se muestra el área real de la figura. En la figura 21 se pueden observar las señales de las cinco pruebas que se hicieron con el rectángulo, en las cuales se puede observar que las señales obtenidas oscilan, esto no es tolerable debido afectaran a la presición del sistema.

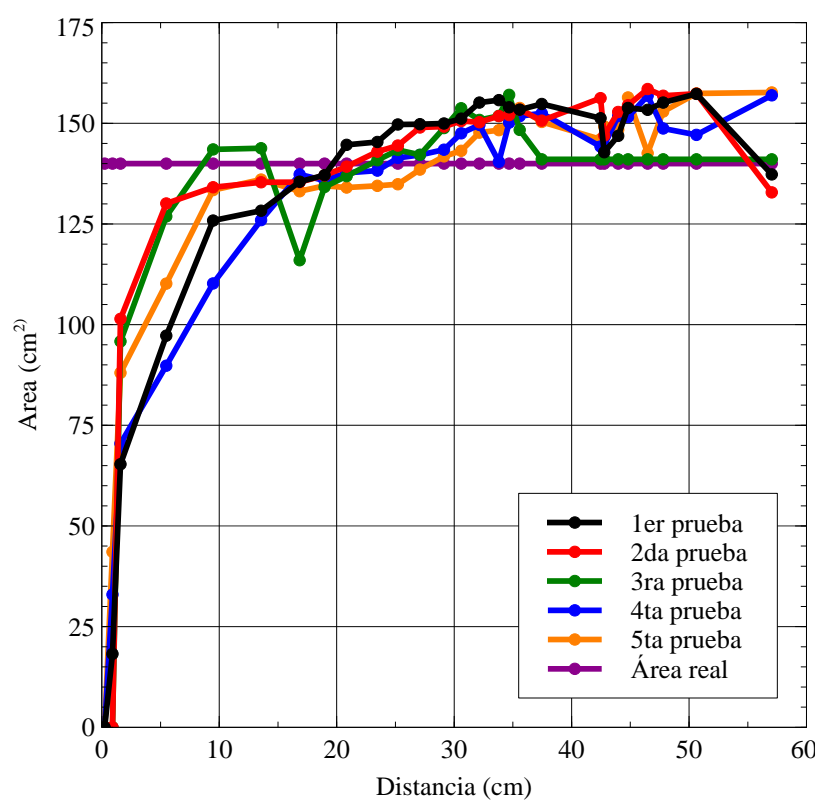

Figura 21 Pruebas realizadas con el rectángulo donde existen oscilaciónes

Para resolver el problema de las osilaciónes se utilizó el filtro EMA con un $\alpha=$ 0.2 obteniendo los resultados mostrados en la figura 22.

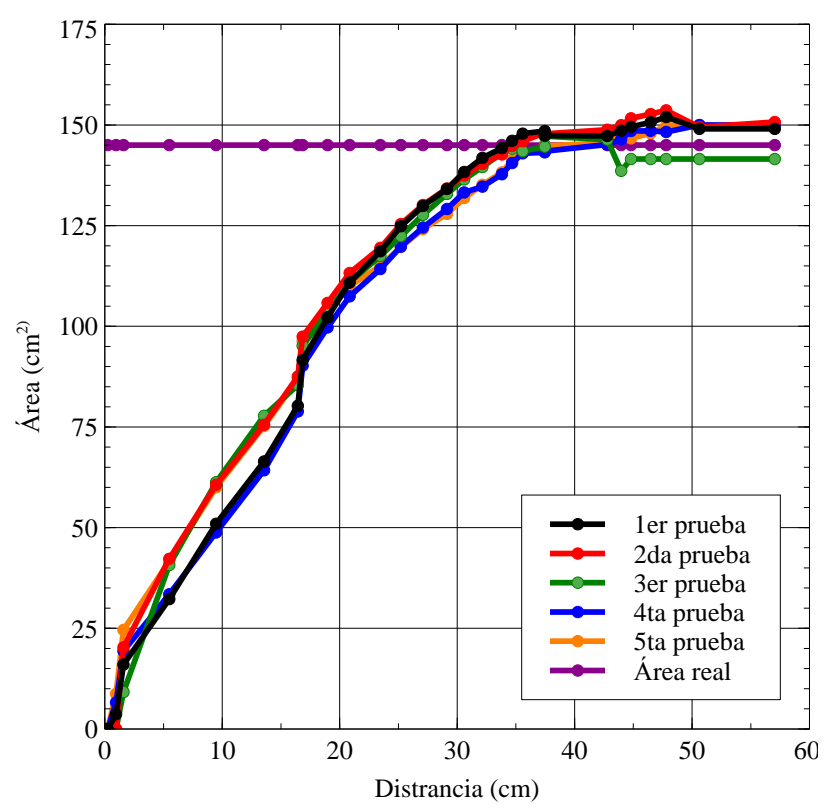

Figura 22 Pruebas realizadas con el rectángulo donde las oscilaciónes son controladas gracias al filtro

La figura 22 muestra que al aplicar el filtro es posible mejorar la precisión del sistema ya que gracias a la utilización del filtrado es posible eliminar oscilaciones que pueden afectar la toma de datos.

En la figura 23 se muestran los resultados de las pruebas con el triángulo antes de la aplicación del filtro. 


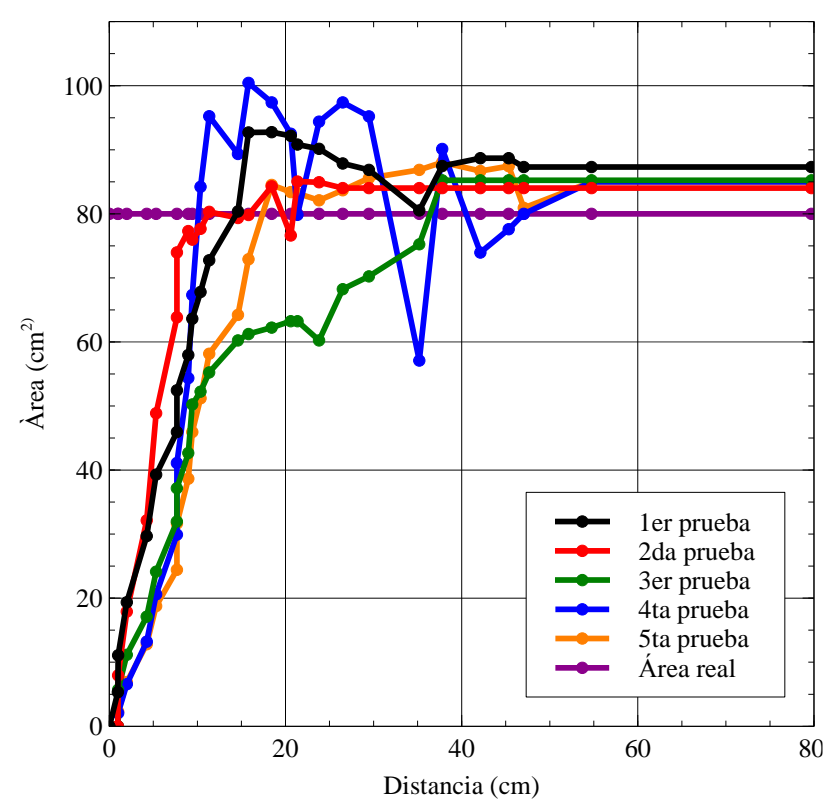

Figura 23 Pruebas realizadas con el triángulo donde existen oscilaciónes que afectan al sistema

En la figura 23 se puede observar que las diversas pruebas realizadas presentan oscilaciones por lo que se recurrio a la utilización de filtros para suprimir las oscilaciones, el resultado se muestra en la figura 24.

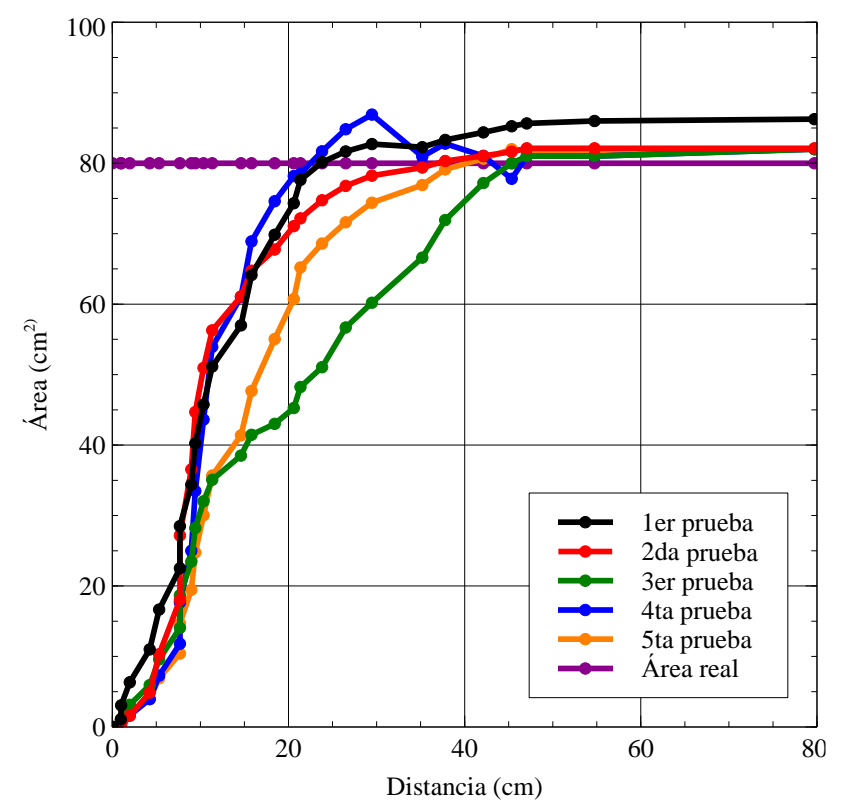

Figura 24 Pruebas realizadas con el triángulo utilizando un $\alpha=0.2$

La utilización del filtro permitió mejorar la lectura del área, por lo que se puede observar en la figura 24 que se mejoro la presición de obtención de la msima.

Las pruebas realizadas con el hexágono se observan en la figura 25 donde se muestran las graficas de medición de área sin filtrado.

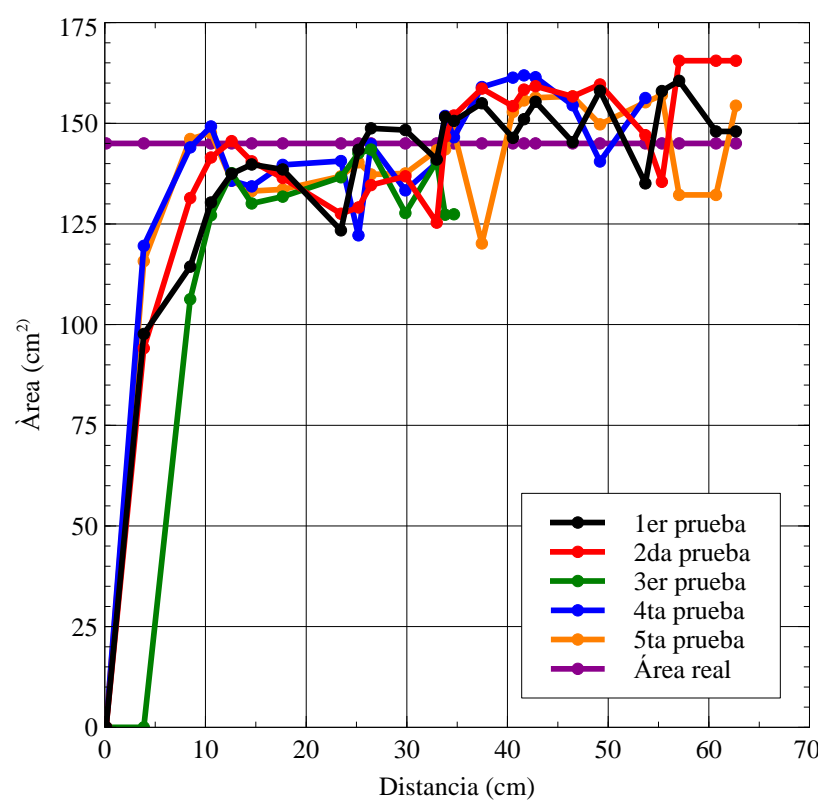

Figura 25 Pruebas realizadas con el hexágono donde existen oscilaciónes que afectan al sistema

La figura 25 muestra que las cinco pruebas realizadas presentan oscilaciones dentro del área real de la figura, por lo que se mejoro la presición aplicando el filtrado de señales, los resultados de la aplicación del filtro se pueden observar en la figura 26.

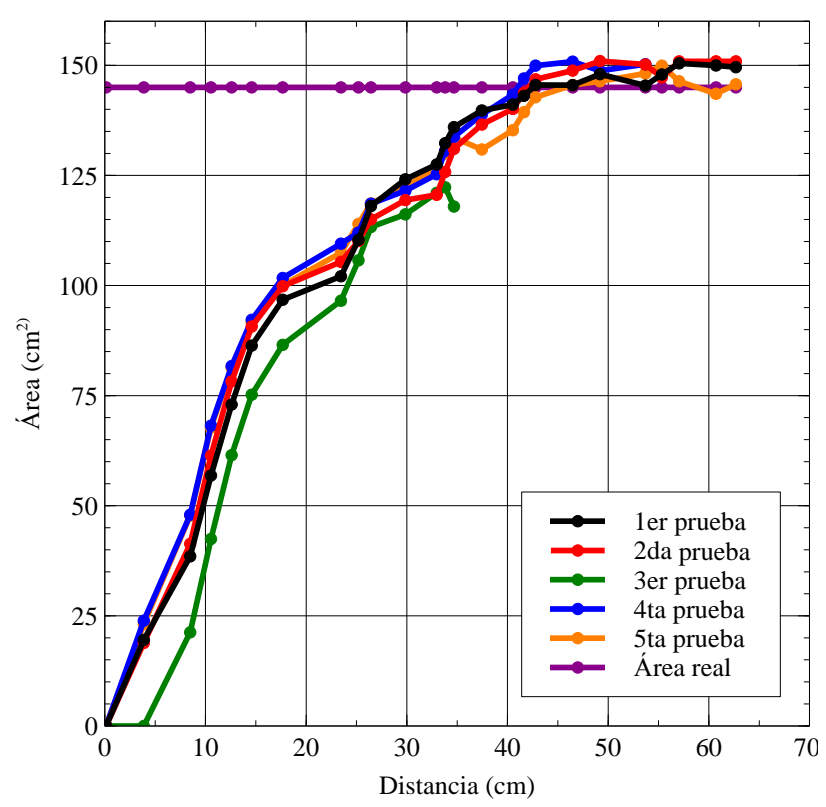

Figura 26 Pruebas realizadas con el hexágono utilizando un $\alpha=0.2$ para atenuar osilaciones

En la figura 26 se observa que el filtrado de las señales mejoro la presición del área medida con el área real, esto permitirá obtener lecturas mas estables del área.

TORRES-BECERRA, Franco Javier, GUZMAN-ALTAMIRANO, Miguel Angel, GARCÍA-GALLEGOS, Jesús Hazael y CABAL-VELARDE, Javier Gustavo. Diseño e implementación de un sistema de visión por computadora para el reconocimiento de objetos en movimiento. Revista de Simulación Computacional. 2019 
Al hacer pruebas con el pentágono, la lectura del area en las cinco pruebas presentaron altas oscilaciones, en la figura 27 se puede observar el comportamiento del área del pentagono, por lo que se procede a aplicar filtros para mejorar la señal.

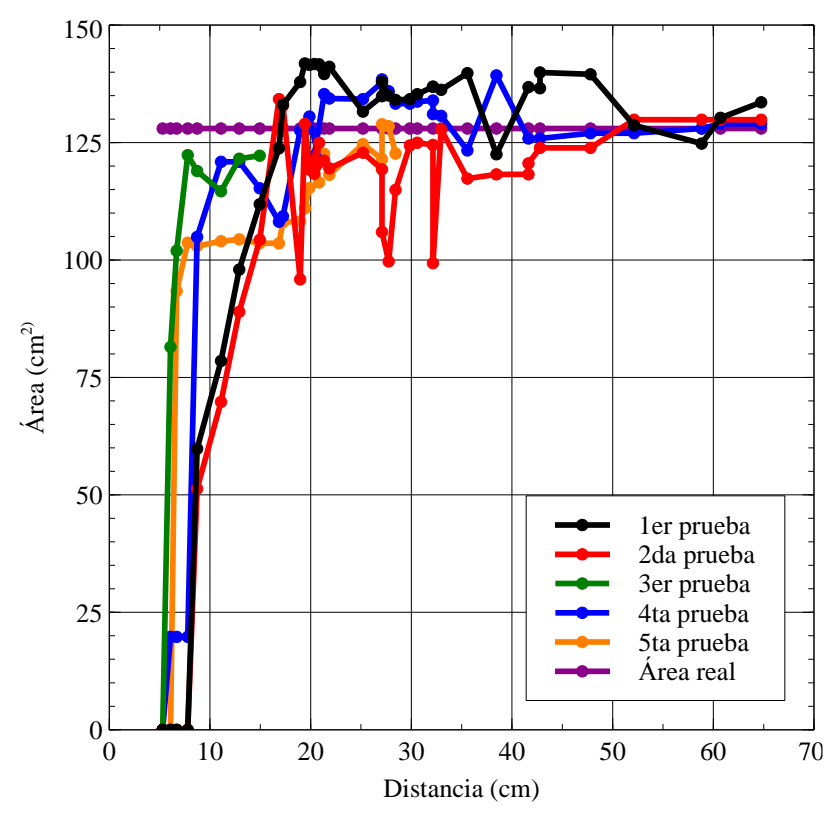

Figura 27 Pruebas realizadas con el pentágono donde se muestra la variación del área

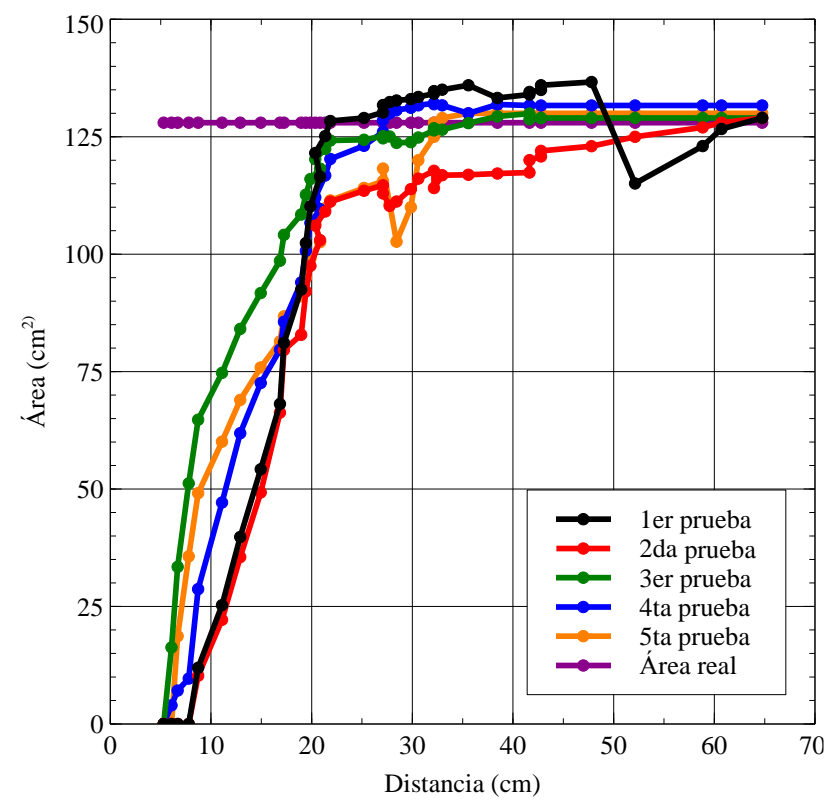

Figura 28 Pruebas realizadas con el pentágono utilizando un $\alpha=0.2$

La figura 28 muestra que a pesar de la utilización de filtros el sistema sigue presentando oscilaciones, las pruebas mas cercanas al valor real del área del pentágono fueron la prueba 3, 4 y 5. Las pruebas realizadas con el círculo, se muestran en la figura 29, donde se puede observar que hay oscilaciones cercanas rondando por el área real del la figura.

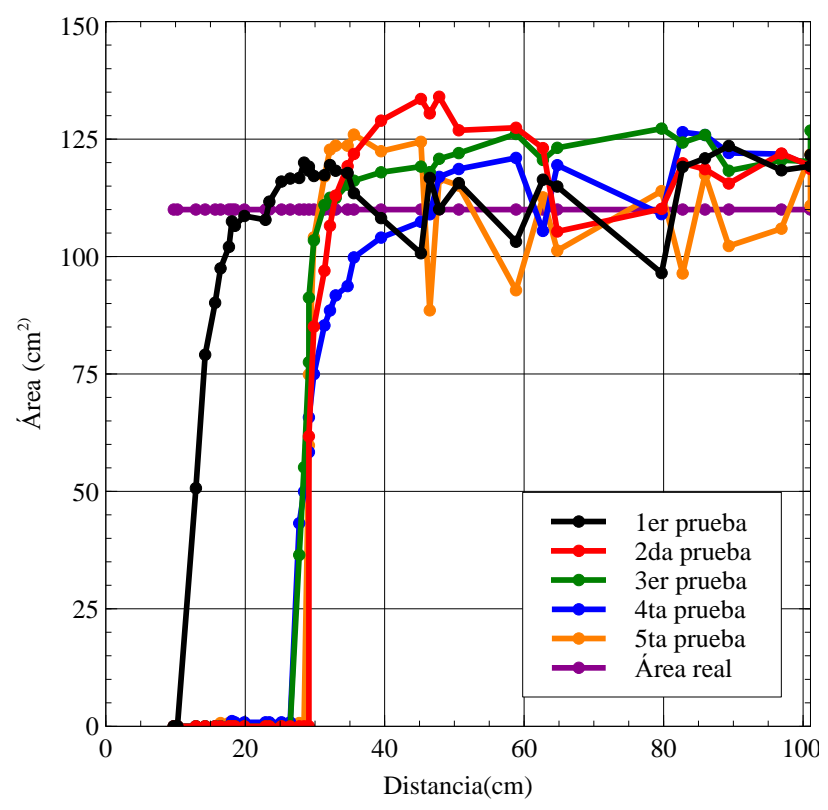

Figura 29 Pruebas realizadas con el círculo donde el área presenta oscilaciónes

En la Figura 30 se observan las gráficas filtradas de las pruebas, donde se observa que se logra eliminar la oscilación pero presenta divergencia del área real en algunas pruebas.

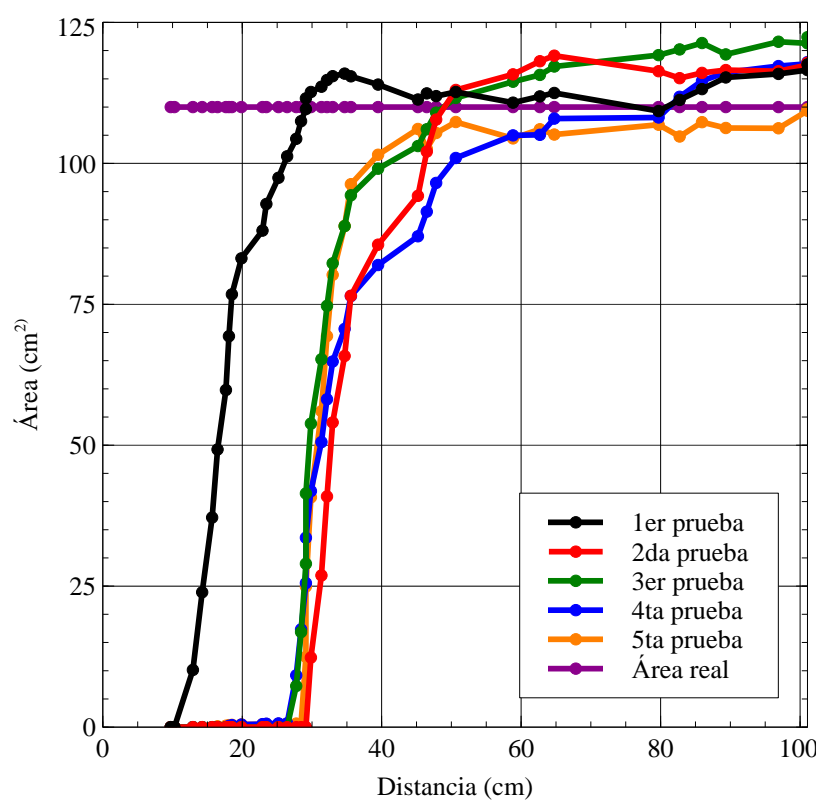

Figura 30 Pruebas realizadas con el círculo utilizando un $\alpha=0.2$

\section{Variación del area con cambios de iluminación}

Para la realización de las pruebas se utilizo un dimmer para poder variar la intensidad de luz, este se colocó a un nivel de 30\%, 60\% y $90 \%$ respectivamente, esto con el fin de observar si existe algun cambio de área. En la figura 31 se muestra el cambio del área a diferentes niveles de iluminación. 


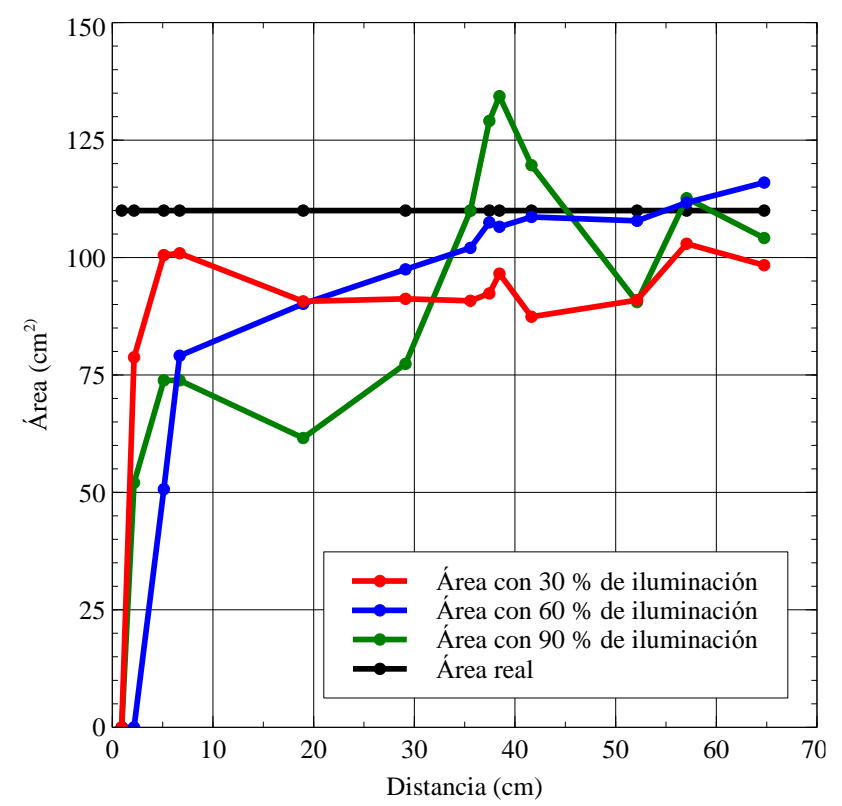

Figura 31 Variación del área del círculo con diferentes niveles de iluminación

Como se puede observar en la figura 31 el área tiene una variación de acuerdo al cambio de iluminación, pero tambien lo que presentan las señales es mayor concentración de ruido, la señal con iluminación al $90 \%$ presenta grandes cambios de área, mientras que la señal con iluminación al $60 \%$ presenta un cambio de área menor y la señal con iluminación al $30 \%$ presenta un área divergente con el área real ademas de que esta presenta menos distancia al momento del reconocimiento de la figura. En la figura 32 se muestra la gráfica del cambio de área pero ya con señales filtradas.

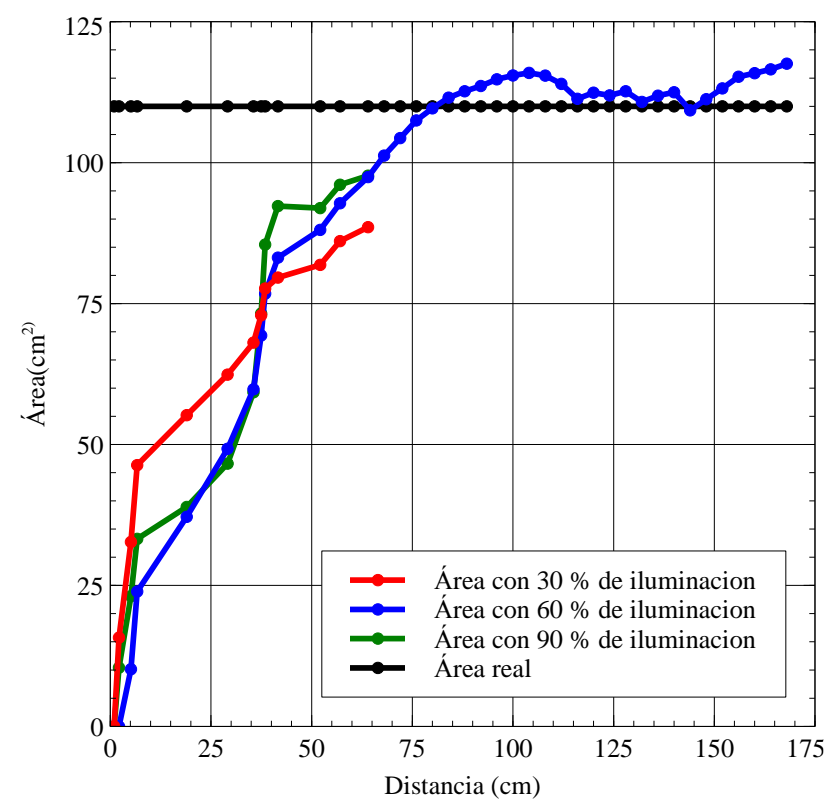

Figura 32 Variación del área del círculo con diferentes niveles de iluminación, señales filtradas
En la figura 32 se puede observar que al aplicar el filtro EMA, el cambio de área con iluminación al $30 \%$ presenta una divergencía del área real de la figura, a su vez el cambio de área con una iluminación al 90\% tambien diverge del área real, mientras que el cambio de área con iluminación al $60 \%$ presenta poca divergencia al área real al momento de variar la distancia. La figura 33 muestra los cambios del área del rectangulo utilizando los mismos cambios de iluminación.

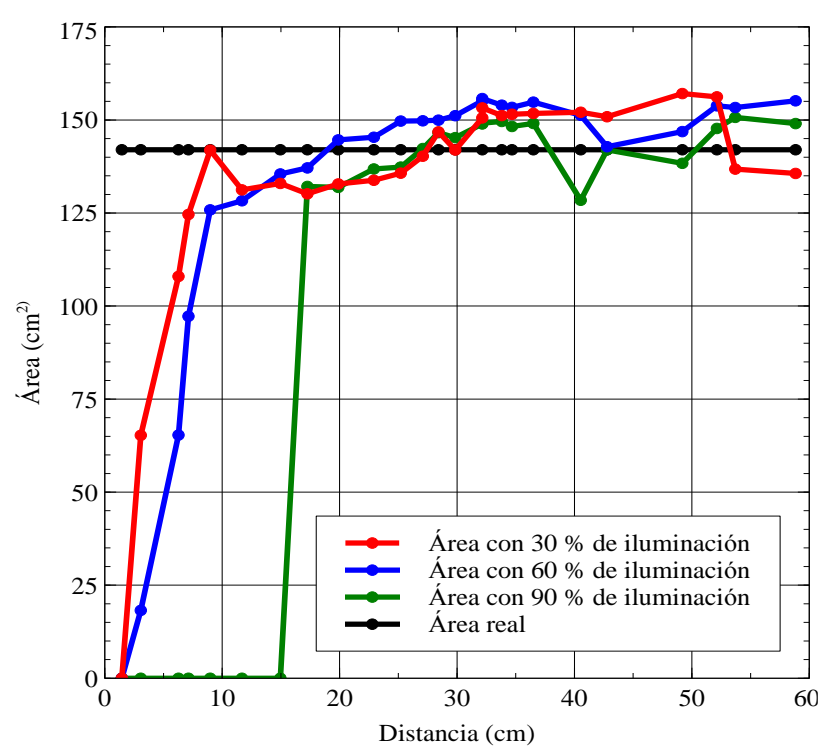

Figura 33 Variación del área del rectángulo con diferentes niveles de iluminación

En la Figura 33 se puede observar que la variación del área utilizando los distintos niveles de iluminación presenta oscilaciones por lo que fue necesario filtrar las señales para determinar cual es la mejor opción de iluminación, en la figura 34 se pueden observar las señales filtradas.

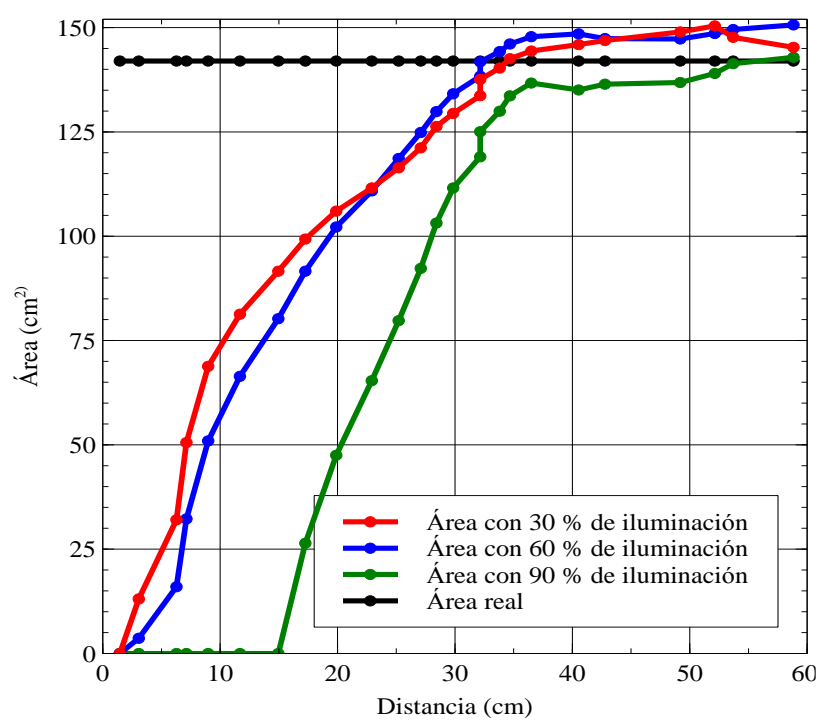

Figura 34 Variación del área del rectángulo con diferentes niveles de iluminación, señales filtradas

TORRES-BECERRA, Franco Javier, GUZMAN-ALTAMIRANO, Miguel Angel, GARCÍA-GALLEGOS, Jesús Hazael y CABAL-VELARDE, Javier Gustavo. Diseño e implementación de un sistema de visión por computadora para el reconocimiento de objetos en movimiento. Revista de Simulación para el reconocimiento de objetos en movimiento. Revista de Simulación 
En la figura 34 se puede observar que la iluminación al $60 \%$ es la mejor opción, ya que esta presenta menos oscilaciones respecto a las otras, ademas que de que al utilizar una iluminación al $90 \%$ se presenta lentitud en el sistema al momento de la determinación del área. La figura 35 muestra los cambios de área del triángulo utilizando los mismos parámetros de iluminación.

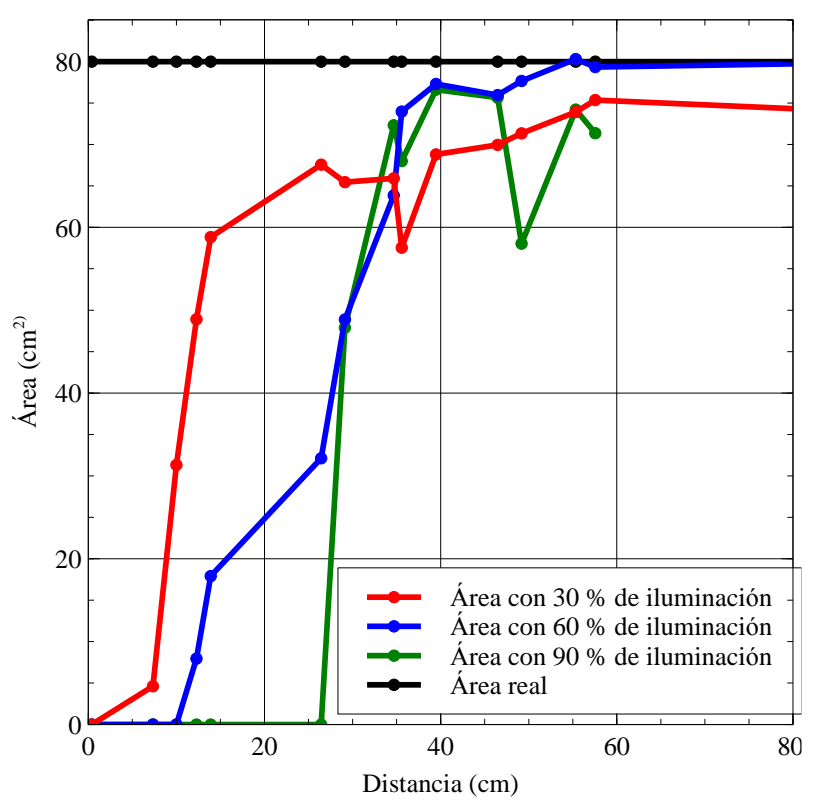

Figura 35 Variación del área del triángulo con diferentes niveles de iluminación

La figura 35 muestra que para obtener mejores resultados de área se debe utilizar la iluminación al $60 \%$ ya que esta presenta muy pocas oscilaciones respecto a las otras dos gráficas, para mejorar la presición la figura 36 muestra las señales filtradas.

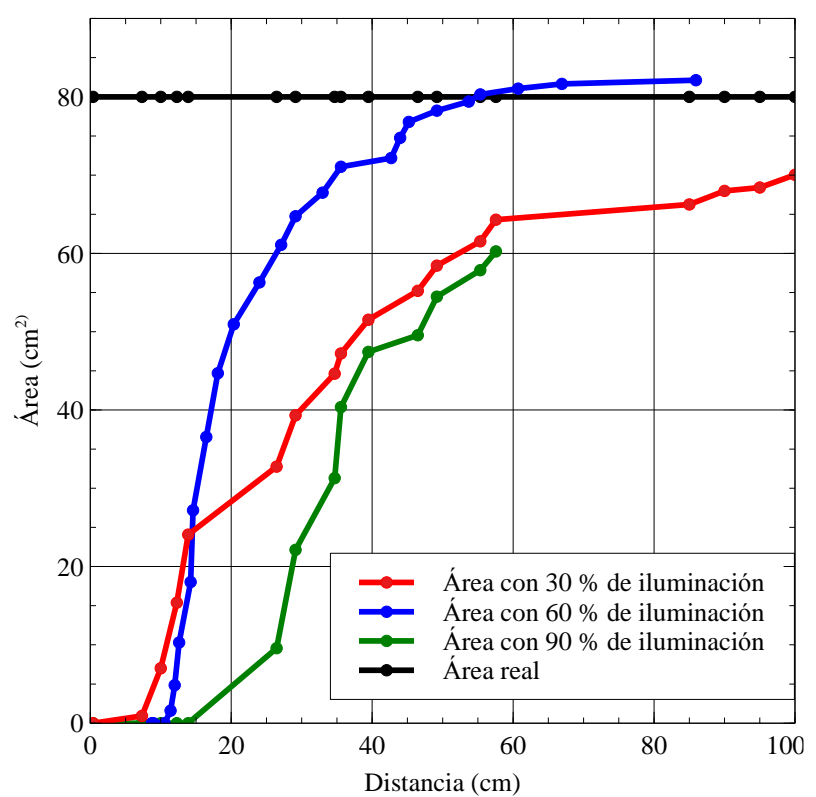

Figura 36 Variación del área del triángulo con diferentes niveles de iluminación, señales filtradas
En la figura 36 se muestra que al utilizar la iluminación al $30 \%$ y al $90 \%$ ocasiona que el área sea divergente al área real, mientras que al utilizar un nivel de iluminación al $60 \%$ el área dejar de presentar osilaciones a cierta distancia. La figura 37 muestra los cambios de área del pentágono utilizando los mismos tres niveles de iluminación.

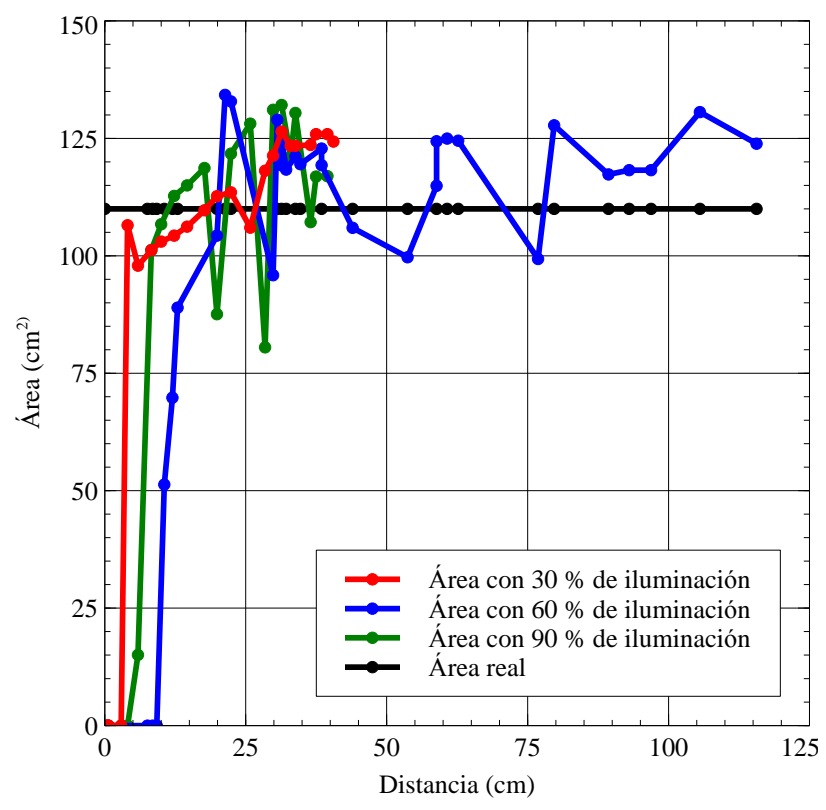

Figura 37 Variación del área del pentágono con diferentes niveles de iluminación

La figura 37 muestra que al obtener el área del pentagono se presentan oscilaciones utilizando los tres niveles de iluminación, para determinar cual es el mejor nivel de iluminación se filtraron las señales, estas pueden observarse en la figura 38

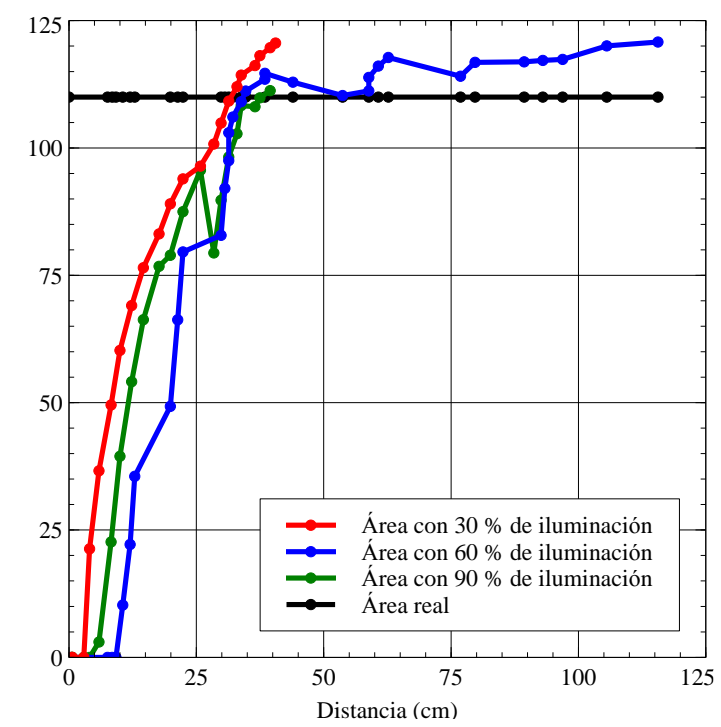

Figura 38 Variación del área del pentágono con diferentes niveles de iluminación, señales filtradas

TORRES-BECERRA, Franco Javier, GUZMAN-ALTAMIRANO, Miguel Angel, GARCÍA-GALLEGOS, Jesús Hazael y CABAL-VELARDE, Javier Gustavo. Diseño e implementación de un sistema de visión por computadora para el reconocimiento de objetos en movimiento. Revista de Simulación Computacional. 2019 
En la figura 38 las señales presentan oscilaciones a pesar de haberles aplicado un filtro, por lo que la gráfica de área mas cercana al valor de área real es la del $60 \%$ de iluminación, mientras que las otras divergen del valor de área real. La figura 39 muestra las gráficas del cambio de área del hexagono sometidas a los niveles de iluminación utilizados.

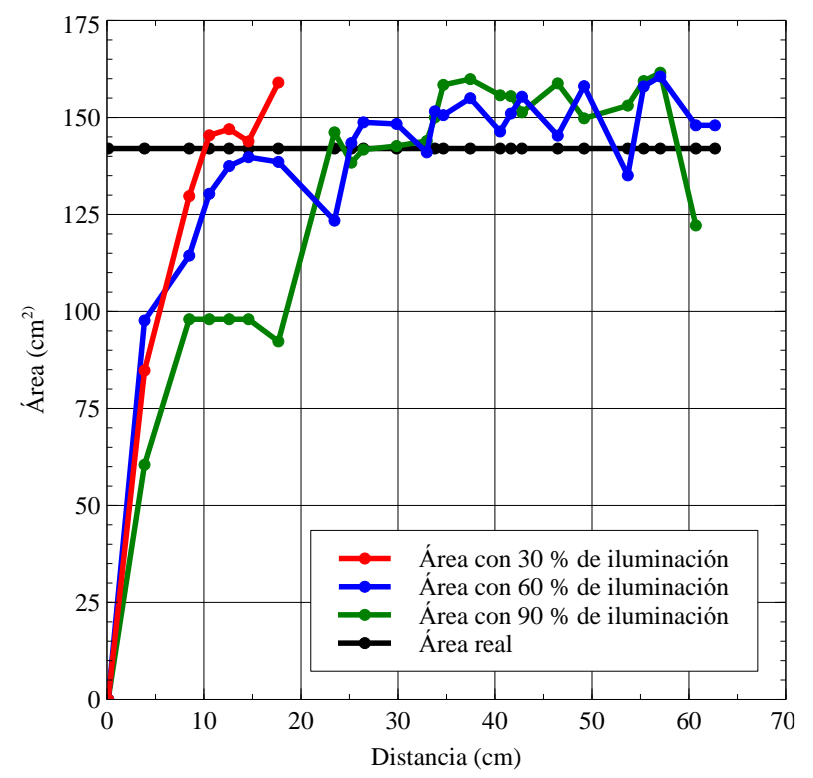

Figura 39 Variación del área del hexágono con diferentes niveles de iluminación

Las señales presentadas en la figura 39 donde se muestra que el área medida del hexágono se afecta con la iluminación al 90\%, ya que presenta altas oscilaciones, mientras que las oscilaciones utilizando los otros niveles iluminación son menores, para mejorar esto se filtraron las señales, esto se muestra en la figura 40.

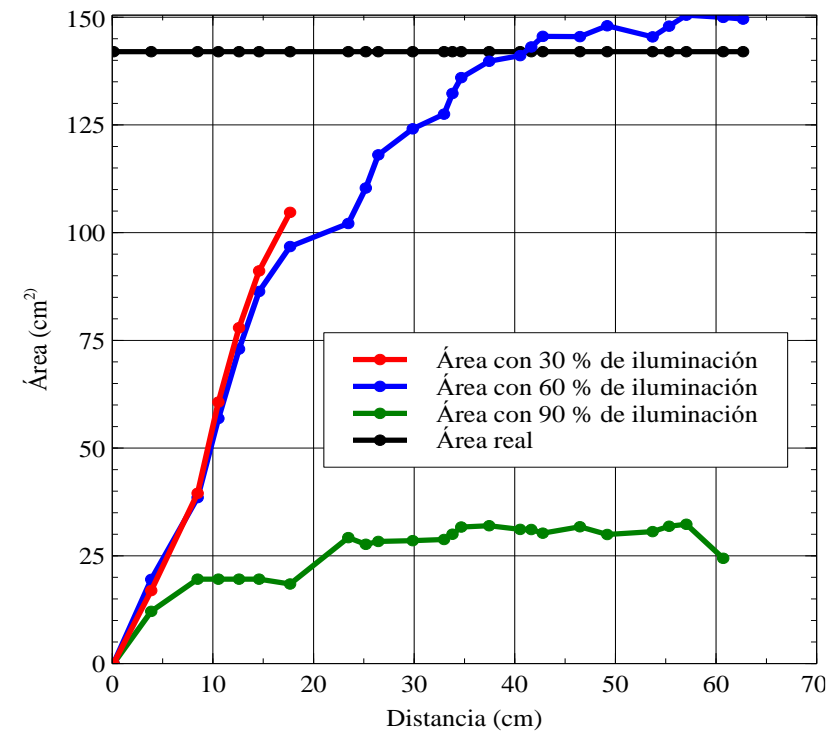

Figura 40 Variación del área del hexágono con diferentes niveles de iluminación, señales filtradas
Las figura 40 muestra que al utilizar la iluminación al $60 \%$ el área es mas estable y mas cercana al área real, mientras que utilizando los otros dos niveles de iluminación el área medida diverge totalmente del área real.

\section{Conclusión}

Con el trabajo realizado se logro hacer el reconocimiento de figuras geometricas de acuerdo a su morfología, a su vez el sistema mostro una buena presición en la obtención del área de un figura de interes sin importar si la figura se encuentra alejada o cerca del panorama de visión de la cámara, cabe destacar que esto es importante debido a que en el reconocimiento en tiempo real existen diversos parametros a considerar como el ruido en la imagen o la iluminación y velocidad de desplazamiento.

\section{Referencias}

[1]Estarita, J., et al., Sistema de Reconocimiento de objetos en tiempo real. 2017. 8(2): p. 41-45.

[2]Caballero Barriga, E.R., Aplicación práctica de la visión artificial para el reconocimiento de rostros en una imagen, utilizando redes neuronales y algoritmos de reconocimiento de objetos de la biblioteca opencv. 2017.

[3]Marino-Vera, H., L.E. Mendoza, and O.E.J.R.d.I. Gualdrón-Guerrero, Desarrollo e Innovación, Medición automática de variables antropométricas para la evaluación de la respiración usando visión artificial. 2017. 8(1): p. 161-169.

[4]Rosales Romero, C.E., Prototipo de detección de expresiones corporales mediante visión artificial para mejorar la comunicación con niños que tienen parálisis cerebral infantil. 2017.

[5]Ruiz-Sarmiento, J.-R., C. Galindo, and J.J.A.d.1.X.J.d.A. Gonzalez-Jimenez, Modelado del contexto geométrico para el reconocimiento de objetos. 2017.

[6]FLORES-MONTES, M.Á., MEDINAMUÑOZ, Luis Arturo, MAYORQUÍNROBLES, Jesús, GARCÍAMUÑOZ, Omar Adrián, Sistema de detección de incendios basado en visión artificial. Revista de Prototipos Tecnológicos, 2017. 3: p. 6. 
[7]Kumar, T. and K.J.I.J.o.C.A. Verma, $A$ Theory Based on Conversion of RGB image to Gray image. 2010. 7(2): p. 7-10.

[8]OpenCV. Color conversion. 2015 [cited 2019.

[9]Gonzalez, R.C., R.E. Woods, and S.L. Eddins, Digital Image Processing Using MATLAB. 2003: Prentice-Hall, Inc.

[10]Otsu, N.J.I.t.o.s., man, and cybernetics, $A$ threshold selection method from gray-level histograms. 1979. 9(1): p. 62-66.

[11]Al-Amri, S.S. and N.V.J.a.p.a. Kalyankar, Image segmentation by using threshold techniques. 2010.

[12]ROSAS-ARIAS, L., et al., Robot clasificador de objetos de color utilizando técnicas de filtrado RGB. p. 50.

[13]Green, B.J.R.M., Canny edge detection tutorial. 2002. 6: p. 2005.

[14]Perona, P., J.J.I.T.o.p.a. Malik, and m. intelligence, Scale-space and edge detection using anisotropic diffusion. 1990. 12(7): p. 629639.

[15]Cao, Y.-T., et al., Circle Marker Based Distance Measurement Using a Single Camera. 2013. 1(4): p. 376.

[16]P., P. Exponential Moving Average. 2019. 